\title{
Thyroid Hormones and Mesotherapy
}

\author{
Husnia I. Marrif* \\ Department of Pharmacology and Toxicology, College of Pharmacy and Health Sciences, Ajman University of Science and Technology, Al-Fujairah, UAE \\ ${ }^{*}$ Correspondence: husnia.marrif@mail.mcgill.ca
}

Thyroid hormones are the master regulator of body metabolism and growth. They act at molecular level to manipulate genes and cellular functions to balance the basic metabolic rate. They bind to superfamily of nuclear receptors that recognize discrete sequences of DNA and act as transcription factors (Renkawitz et al., 1996).

At the cellular level, thyroid hormones act directly on the mitochondria. Uncoupling of mitochondrial energy production and dissipation of energy as heat are believed to be the main mechanism of losing energy and consequently body weight (Silva and Bianco, 2008).

The intimate collaboration of thyroid hormones with the sympathetic system is a major influence of basal body metabolism and fat deposition (Silva and Bianco, 2008). Epinephrine binds to Sympathetic Beta Receptor and mediates fat breakdown "lipolysis" and subsequently body weight (Dodt et al., 2003).

The search for the perfect weight loss formula became the holy grill mission for many pharmaceutical companies. Among many products and techniques used to manage body countering and weight loss is Mesotherapy. The controversial technique gained popularity in different countries, and recently introduced to North America. It was established by Michel Pistor in 1952 (Olivero-Rivera, 2008) and its principals depend on injecting pharmaceutical agents and or nutrients into the mesodermal layer of the skin.
Thyroid hormones are being used in injectable cocktails for losing weight (Kim et al., 2010). The use of thyroid hormones in Mesotherapy is not supported by testing in preceding clinical trials.

The argument to use thyroid hormones for a transient and defiantly none permanent cosmetic procedure will be left to the better judgment of cosmetic experts. However, the legitimate concern from medical as well as from pharmaceutical point of view would be the dosing, effectiveness, and unwanted side effects associated with those hormones.

Beside the reported side effects associated with Mesotherapy such as infection (Correa et al., 2010), the use of powerful hormones by, in some cases, non-medical staff did not go without complications. For instance, a case of factitious thyrotoxicosis was reported after using cocktail containing Triiodothyroacetic acid (Danilovic et al., 2008).

Beside hormones, other pharmaceutical agents such as Epinephrine and Aminophylline are also used in fat reduction Mesotherapy cocktails (Kim et al., 2010). In light of the previously mentioned factitious thyrotoxicosis case, systemic absorption seems to be an issue in supposedly localized technique and it could be a major contributor to side effects. Due to powerful effect of hormones on cells, tissue, and vascular system, the unorthodox use of hormones and more specifically thyroid hormones in Mesotherapy should be strictly regulated to avoid serious side effects and to guarantee some benefits if any.

\section{REFERENCES}

Correa, N. E., Cataño, J. C., Mejía, G. I., Realpe, T., Orozco, B., Estrada, S., Vélez, A., Vélez, L., Barón, P., Guzmán,A., and Robledo, J. (2010). Outbreak of mesotherapy-associated cutaneous infections caused by Mycobacterium chelonae in Colombia. Jpn. J. Infect. Dis. 63, 143-145.

Danilovic, D. L., Bloise, W., Knobel, M., and Marui, S. (2008). Factitious thyrotoxicosis induced by mesotherapy: a case report. Thyroid 18, 655-657.

Dodt, C., Lönnroth, P., Wellhöner, J. P., Fehm, H. L., and Elam, M. (2003). Sympathetic control of white adipose tissue in lean and obese humans. Acta Physiol. Scand. 177, 351-357.

Kim, J. B., Moon, W., Park, S. J., Park, M. I., Kim, K. J., Lee, J. N., Kanq, S. J., Janq, L. L., and Chanq, H. K (2010). Ischemic colitis after mesotherapy combined with anti-obesity medications. World J. Gastroenterol. 16, 1537-1540.

Olivero-Rivera, L. (2008). Mesotherapy for body sculpting. European staple of reshaping gaining ground here. Adv. Nurse Pract. 16, 30.

Renkawitz, R., Kaltschmidt, C., Leers, J., Martin, B., Muller, M., and Eggert, M. (1996). Enhancement of nuclear receptos transcriptional signaling. J. Steroid Biochem. Mol. Biol. 56, 39-45.

Silva, J. E., and Bianco, S. D. (2008). Thyroid adrenergic interactions: physiological and clinical implications. Thyroid 18, 157-165.

Received: 31 January 2011; accepted: 08 February 2011; published online: 23 February 2011.

Citation: Marrif HI (2011) Thyroid Hormones and Mesotherapy. Front. Endocrin. 2:5. doi: 10.3389/ fendo.2011.00005

This article was submitted to Frontiers in Thyroid Endocrinology, a specialty of Frontiers in Endocrinology. Copyright (c) 2011 Marrif. This is an open-access article subject to an exclusive license agreement between the authors and Frontiers Media SA, which permits unrestricted use, distribution, and reproduction in any medium, provided the original authors and source are credited. 